\title{
Progressing towards tuberculosis elimination in the European Union and European Economic Area
}

M J van der Werf (marieke.vanderwerf@ecdc.europa.eu) ${ }^{1}$, D Antoine ${ }^{2}$

1. European Centre for Disease Prevention and Control (ECDC), Stockholm, Sweden

2. Institut de Veille Sanitaire, Saint Maurice, France

van der Werf MJ, Antoine D. Progressing towards tuberculosis elimination in the European Union and European Economic Area. Euro Surveill. 2015;20(11):pii=21066. Available online: http://www.eurosurveillance.org/ViewArticle.aspx?Articleld=21066

Article submitted on 17 March 2015 / published on 19 March 2015

The year 2015 marks the year by which the Stop TB partnership Global Plan, in line with the United Nations Millennium Development Goal (MDG) 6 on HIV/AIDS, malaria and tuberculosis (TB), committed to meet the target to halt and begin to reverse the incidence of tuberculosis (TB) $[1,2]$.

On the occasion of World Tuberculosis Day on 24 March, the World Health Organization Regional Office for Europe (WHO/Europe) and the European Centre for Disease Prevention and Control (ECDC) annually publish a joint report on TB surveillance and monitoring, based on data collected at national level in the European Union (EU)/European Economic Area (EEA) countries and countries in the WHO European Region overall. This report allows to assess the progress made towards prevention and control of TB in the EU/EEA and in the WHO European Region.

The latest report shows that in 2013, a total of 64,844 TB cases were reported in $30 \mathrm{EU} / \mathrm{EEA}$ countries, 6\% $(4,175$ cases) less than in 2012 [3]. Notification rates already started to decline before 2004 [4] and this decline continued in the past 10 years, i.e. from 19.1 in 2004 to 12.7 TB cases per 100,000 population in 2013 $[3,5]$. Thus the target set for TB in the MDG 6 has been reached, and suggests that effective TB programmes are in place in the EU/EEA. Overall, the 2013 TB surveillance data show no significant changes from trends observed in previous years. Remarkably, the proportion and number of cases with multidrug-resistant (MDR) TB remained virtually unchanged between 2008 and 2013: EU/EEA countries reported 1,484 MDR TB cases ( $4.1 \%$ of cases with drug susceptibility testing (DST) results) and 139 extensively drug-resistant (XDR) TB cases.

A tool frequently used for TB prevention, especially to prevent severe forms of TB in children, is the Bacillus Calmette-Guérin (BCG) vaccine. According to the International Union Against Tuberculosis and Lung Disease, countries that reach a low TB incidence may consider discontinuation of universal BCG vaccination [6]. In 2007, France changed its BCG vaccination policy from universal BCG vaccination to vaccination of children considered to be at high-risk for TB [7]. In this issue of Eurosurveillance, Bui et al [8] present results of an evaluation of the impact of the changed policy and show that TB meningitis incidence did not increase and remained rare in France. However, the authors also point out the need to continue to carefully monitor the impact of the selective vaccination policy. Their study provides a good example of how new policies for TB vaccines can be evaluated using both notification and laboratory data.

To target prevention and control activities, experts need to know the specifics of 'their' epidemic. In many EU/EEA countries, HIV status of TB cases remains unknown at the national level [3]. McDonald et al. in this issue, used probabilistic data linkage of anonymised TB and HIV patient data to investigate the extent of TB and HIV co-infection and to identify risk factors for such co-infections in Scotland [9]. They concluded that TB and HIV co-infection was relatively uncommon in Scotland and that co-infected patients belonged to certain risk populations. Clinicians should be aware of the possibility of co-infection and take appropriate diagnostic measures in these groups. In countries where HIV cases are reported anonymously or where patient confidentiality legislation prevents collection of information on HIV status for individual TB patients, record linkage is a good method for gathering information on TB-HIV co-infections to better target prevention and control measures.

The epidemiological situation of TB in Europe is overall improving. However, this may mask some disparities between countries. In 2013, TB incidence ranged from less than 10 per 100,000 population in 18 countries to over 40 per 100,000 in three countries in the EU/EEA [3]. MDR and XDR TB persist and high rates of MDR TB are reported in neighbouring countries of the EU/EEA. Furthermore, the proportion of patients who successfully completed their treatment is still below the WHO target of $85 \%$ in a large number of the EU/ EEA countries. In countries with low notification rates 
TB is concentrating in vulnerable populations such as in people originating from countries with a high TB burden, the urban poor, and prisoners. This results in TB notification rates of $>40$ per 100,000 population in some cities in low incidence countries [10]. For all these reasons, TB is still a public health concern across Europe.

The long-term goal for the EU is to control and ultimately eliminate TB [11]. In order to progress further towards this goal it is essential to target prevention and control activities so that they fit the epidemiological situation in the respective countries or areas. This includes, for example, maintaining expertise and awareness on TB in low incidence settings and tailoring TB control measures to the most at risk populations. Also, efforts should be maintained to ensure good quality TB programmes that enable prompt identification and adequate management of TB patients as well as necessary infection control measures. Furthermore, existing tools need to be better implemented, i.e. diagnostic tests, medicines, and vaccines, and new tools need to be developed and introduced. Therefore, investments in research and development of new tools on TB need to continue and even expand.

Elimination of TB and MDR TB in the EU/EEA and its Eastern Partnership countries is the topic of the 'Eastern Partnership Ministerial Conference on Tuberculosis (TB) and its multidrug resistance' organised by the Latvian Presidency of the Council of the EU, in Riga, Latvia, on 30 and 31 March 2015 [12]. At this conference, ministers and high level representatives from Ministries of Health, Social Affairs and Finance of the EU/EEA and Eastern Partnership countries as well as high level representatives of the European Commission, members of the European Parliament, representatives of international institutions and non-governmental organisations, and communities and people affected by TB, will discuss intergovernmental and multi-sectorial collaboration to boost commitment and favourably impact on the TB burden. It is expected that this conference should accelerate progress towards TB elimination in the EU/EEA and beyond.

Conflicts of interest

None declared.

\section{Authors' contributions}

MvdW and DA jointly drafted the manuscript and both approved the final version.

\section{References}

1. Stop TB Partnership and World Health Organization (WHO). The global plan to stop TB, 2006-2015. Geneva: WHO; 2006 Available from: http://www.stoptb.org/assets/documents/ global/plan/GlobalPlanFinal.pdf

2. Millenium development goals and beyond 2015. Goal 6: combat HIV/AIDS, malaria and other diseases. United Nations.
[Accessed: 12 March 2015]. Available from: http://www.un.org/ millenniumgoals/aids.shtml

3. European Centre for Disease Prevention and Control (ECDC)/ WHO Regional Office for Europe. Tuberculosis surveillance and monitoring in Europe 2015. Stockholm: ECDC; 2015. Available from: http://ecdc.europa.eu/en/publications/Publications/ tuberculosis-surveillance-monitoring-Europe-2015.pdf

4. EuroTB and the national coordinators for tuberculosis surveillance in the WHO European Region. Surveillance of tuberculosis in Europe. Report on tuberculosis cases notified in 2004. Saint-Maurice: Institut de Veille Sanitaire; 2006. Available from: http://ecdc.europa.eu/en/publications/ Publications/SUR_TB_EuroTB_Annual_report_2004_full\%20 report.pdf

5. European Centre for Disease Prevention and Control (ECDC)/ WHO Regional Office for Europe: Tuberculosis surveillance in Europe 2008. Stockholm: ECDC; 2010. Available from: http:// www.euro.who.int/_data/assets/pdf_file/0007/78856/ E93600.pdf

6. Criteria for discontinuation of vaccination programmes using Bacille Calmette-Guerin (BCG) in countries with a low prevalence of tuberculosis. A statement of the International Union Against Tuberculosis and Lung Disease. Tuber Lung Dis. 1994;75(3):179-80. http://dx.doi.org/10.1016/09628479(94)90003-5 PMID:7919307

7. Guthmann JP, Antoine D, Fonteneau L, Che D, Lévy-Bruhl D. Assessing BCG vaccination coverage and incidence of paediatric tuberculosis following two major changes in BCG vaccination policy in France. Euro Surveill. 2011;16(12):19824. PMID:21457685

8. Van Bui T, Lévy-Bruhl D, Che D, Antoine D, Jarlier V, Robert J. Impact of the BCG vaccination policy on tuberculous meningitis in children under 6 years in metropolitan France between 2000 and 2011. Euro Surveill. 2015;20(11): pii=21064. Available online: http://www.eurosurveillance.org/ViewArticle. aspx?Articleld $=21064$

9. McDonald E, Smith-Palmer A, Wallace LA, Blatchford O. Risk factors for TB and HIV coinfection in Scotland, 2001 to 2010. Euro Surveill. 2015;20(11):pii=21067. Available online: http:// www.eurosurveillance.org/ViewArticle.aspx?Articleld $=21067$

10. de Vries G, Aldridge RW, Cayla JA, Haas WH, Sandgren A, van Hest NA, et al.; Tuberculosis in European Union Big Cities Working Group. Epidemiology of tuberculosis in big cities of the European Union and European Economic Area countries. Euro Surveill. 2014;19(9):20726. http://dx.doi. org/10.2807/1560-7917.ES2014.19.9.20726 PMID:24626208

11. European Centre for Disease Prevention and Control (ECDC). Framework action plan to fight tuberculosis in the European Union. Stockholm: ECDC; 2008. Available from: http://ecdc. europa.eu/en/publications/Publications/0803_SPR_TB_ Action_plan.pdf

12. Ministry of Health of the Republic of Latvia. Eastern partnership Ministerial conference on tuberculosis and its multi-drug resistance. Riga: Ministry of Health of the Republic of Latvia; 2015. Available from: http://www.vm.gov. Iv/en/what_is_new/presidency_events/46_1st_eastern partnership_ministerial_conference_on_tuberculo/ 